\title{
MESOCARPO DE BABAÇU (ORBINYA SP) COMO ADSORVENTE DO DODECIL BENZENO SULFONATO DE SÓDIO (SDBS)
}

\author{
M. S. S. O. GOMES* , J. R. NASCIMENTO \& M. G. O. SILVA \\ Instituto Federal do Maranhão, Campus Bacabal \\ maron@ifma.edu.br
}

Artigo submetido em maio/2015 e aceito em setembro/2016

DOI: $10.15628 /$ holos.2016.3019

\section{RESUMO}

A água é um dos recursos mais utilizados pelos seres vivos, é fundamental para a existência e manutenção da vida e, para isso, deve estar presente no ambiente em quantidade e qualidade apropriadas. Os surfactantes são um grupo de moléculas que apresentam características anfifílicas, tendo variada aplicação na indústria de cosméticos, produtos farmacêuticos, biotecnologia, extração de petróleo e agroquímico uma grande quantidade de surfactante é despejada em ambientes aquáticos, reduzindo a dissolução do oxigênio, causando riscos ambientais para organismos aquáticos. Os ensaios de adsorção foram realizados utilizando-se a farinha do mesocarpo in natura, como adsorvente. Através de medidas de condutividade elétrica foram determinadas a Concentração Micelar Crítica do Dodecil Benzeno Sulfonato de Sódio (SDBS) $\left(3,9 \mathrm{mmolL}^{-1}\right)$, o $\mathrm{pH}_{\mathrm{ZPC}}(6,30)$ e estudos sobre a cinética de equilíbrio, e potencial de remoção do surfactante $(6,5 \%)$.

PALAVRAS-CHAVE: Adsorção, Surfactante, Mesocarpo do Babaçu.

\section{MESOCARP BABASSU (ORBINYA SP) AS ADSORBENT DODECYL BENZENE SODIUM SULFONATE (SDBS)}

\begin{abstract}
Water is one of the most used resources for living beings, it is essential for the existence and maintenance of life and, therefore, must be present in the environment in appropriate quantity and quality. Surfactants are a group of molecules which have amphiphilic character, and varied application in cosmetics, pharmaceuticals, biotechnology, agrochemical oil extraction and a large amount of surfactant is poured into aquatic environments, reducing the dissolution of oxygen causing
\end{abstract}

environmental hazards to aquatic organisms. The adsorption experiments were carried out using the mesocarp fresh flour as adsorbent. By electrical conductivity measurements were determined Critical Micelle Concentration of Sodium Dodecyl Benzene Sulfonate (SDBS) (3.9 mmolL-1), the PHZPC (6.30) and studies on the kinetics of equilibrium, and surfactant removal potential(6,5\%).

KEYWORDS: Adsorbent, Surfactant, Babassu Mesocarp. 


\section{APRESENTAÇÃO}

A preocupação com a qualidade de vida das gerações futuras e a preservação da Terra é um aspecto chave na definição de desenvolvimento sustentável. Conforme Brutland (1991), desenvolvimento sustentável pode ser definido como um desenvolvimento que atende as necessidades do presente, sem ameaçar as necessidades das gerações futuras. A água é um dos recursos mais utilizados pelos seres vivos, é fundamental para a existência e manutenção da vida e, para isso, deve estar presente no ambiente em quantidade e qualidade apropriadas (BRAGA et al., 2002; NANDI et al., 2008).

Atualmente os efluentes vêm sendo contaminados por vários poluentes, dentre estes os surfactantes, do inglês "surface-active agents", significa agente de atividade superficial, são caracterizados por afetar as propriedades físicas de um composto quando adsorvido na sua interface (HOLMBERG, 2003). Os surfactantes conhecidos também com tensoativos são moléculas que possuem características anfifílicas, ou seja, possuem na mesma molécula uma porção hidrofílica ou polar, denominada cabeça, e uma cadeia hidrofóbica ou apolar, a qual é referida como cauda (SHIPOVSKOV et al., 2005).

A presença de duas regiões distintas, em uma mesma molécula faz com que a mesma apresente grande capacidade de adsorção, na sua interface ar-água ou óleo-água assim como na superfície de sólidos (PIRES, 2002). Os surfactantes possuem grande aplicação como aditivos de desempenho para fórmulas em vários setores, como higiene e produtos de limpeza, e em várias aplicações industriais tais como tratamentos de superfície, limpeza industrial, extração de petróleo, agroquímico (TADROS, 2005), são utilizados no tratamento de solos e efluentes contaminados com compostos orgânicos persistentes (ZHENG e OBBARD, 2002).

A contaminação das águas naturais é um dos grandes problemas sociais, que gera preocupação constante e conduz à elaboração de novas normas e regimentos que estabeleçam limites na descarga de contaminantes, a fim de minimizar o impacto ambiental (KUNZ, 2002). Uma considerável quantidade de surfactante é liberada no ambiente, causando problemas de poluição, principalmente em cidades cortadas por rios, onde as pessoas utilizam a água para lavar roupa, louça e veículos (BEZERRA, 2012). Estes surfactantes são responsáveis por causar espuma nos rios e superfície das águas, reduzindo a dissolução do oxigênio na água e causando riscos ambientais para organismos aquáticos (EICHHORN, 2002 apud TAFFAREL, 2010).

Diversos estudos vêm sendo desenvolvidos, na tentativa de solucionar esses problemas de poluição aquática, vários métodos convencionais que buscam remover os tensoativos abrangem processos de alto custo, entretanto a adsorção surgiu como uma alternativa economicamente viável para solucionar alguns problemas de poluição. A adsorção tem característica vantajosa em relação a outros métodos, dentre elas, o baixo custo, a alta eficiência, além de simplicidade, facilidade de execução e insensibilidade a substâncias tóxicas.

Os adsorventes lignocelulósicos mais comuns empregados recentemente na remoção de corantes têxteis e metais, são: mesocarpo de coco (VIEIRA, 2009), bagaço de cana-de-açúcar (OLIVEIRA, 2003), pó de madeira (BONAM et al., 2002) , casca e palha de arroz (KUMAR et al., 2005) e outros resíduos celulósicos, tais como o coco babaçu (AIROLD et al., 2009) e o coco verde (SOUSA et al., 2007) e outros resíduos celulósicos usados in natura ou com superfície modificada para a 
introdução de certos sítios ativos, de melhor eficiência (YOSHIMURA et al., 2006) no entanto nossa proposta é utilizar a farinha do mesocarpo do babaçu in natura, para a remoção do surfactante Dodecil Benzeno Sulfonato de Sódio (SDBS).

A flora brasileira de palmeira de babaçu concentra-se nas regiões Norte, Nordeste e CentroOeste, mas é principalmente no Maranhão que acontece a predominância com 10 dos 18 milhões de hectares existentes no Brasil na sua ocorrência natural, apresentando junto com o Piauí, zonas de alta densidade com população de 200 palmeiras por hectares, o coco se torna muito importante para a grande maioria dos moradores da zona rural, onde ocorre esta palmeira, principalmente no uso de todas as suas partes (MARCOS, 2011).

O fruto do babaçu é composto por quatro partes principais: endocarpo camada externa fibrosa, mesocarpo é a parte do meio do coco formada por uma camada maciça rica em amido, usada como suplemento alimentar tanto para humanos como para animais por ser rica em carboidratos, proteínas e possui propriedade anti-inflamatória e analgésica, e apresenta em sua composição química alguns sais minerais como cálcio, potássio, ferro, sódio, fósforo, magnésio, manganês, alumínio, cobre e chumbo (CARRAZZA et al., 2012); epicarpo camada lenhosa onde ficam fixadas os frutos, e as amêndoas também chamadas de castanha, principal componente do babaçu.

Pouco se sabe da aplicação do mesocarpo de coco babaçu in natura na adsorção, portanto, é de fundamental interesse pesquisar o potencial deste na remoção de poluentes, como os surfactantes.

\section{METODOLOGIA}

\subsection{Materiais e Métodos}

\subsubsection{Tratamento da amostra: lavagem e secagem do mesocarpo}

Pesou-se $8 \mathrm{~g}$ da farinha do mesocarpo em Balança analítica Bel Engineering, em seguida para a obtenção da granulometria utilizou-se peneira de aço do Laboratory Test com abertura de $150 \mu \mathrm{m}$ caixilho $3^{\prime \prime} \times 2^{\prime \prime}$, peneirou-se a farinha e submeteu-se a constantes lavagens com água miliQ, na proporção de 10:1 (água/mesocarpo), as medidas de condutividade forma realizadas antes e após cada lavagem, que se processou sob agitação constante por cerca de 30 minutos em Agitador magnético MAR OLEMAN. As lavagens foram repetidas até condutividade constante. Em seguida o mesocarpo foi seco em estufa Med Clave modelo 4 por $15 \mathrm{~h}$ e $30 \mathrm{~min}$, a temperatura de $65^{\circ} \mathrm{C}$, após esse processo peneirou-se o mesocarpo e armazenou-se no dessecador.

\subsubsection{Concentração Micelar Crítica (CMC)}

Para a determinação da CMC, foram realizados medidas de condutividade utilizando Condutivimetro CG 2000 GEHAKA em função da concentração do surfactante, para isso preparouse solução estoque de $5,5 \mathrm{mmolL}^{-1}$ do surfactante SDBS em $100 \mathrm{~mL}$ de água, em sistema de titulação a partir desta solução obteve-se soluções de concentrações 5,0; 4,5; 4,0; 3,5; 3,0; 2,5; 2,0; 1,$5 ; 1,0 ; 0,5 \mathrm{mmolL}^{-1}$. Cada solução foi posta a agitação constante por período de $3 \mathrm{~min}$ a temperatura de $25^{\circ} \mathrm{C}$, em seguida mediu-se a condutância e registrou-se as leituras. 


\subsection{3 pH Ponto de Carga Zero $\left(p H_{Z P C}\right)$}

Doze soluções padrões do surfactante foram preparadas com concentração de $3,5 \mathrm{mmolL}^{-}$ 1, para tais soluções ajustou-se o $\mathrm{pH}$ entre $1-12$ com soluções de $\mathrm{HCl} / \mathrm{KCl}$ e $\mathrm{NaOH} / \mathrm{KCl}$ de concentração $0,1 \mathrm{~mol} / \mathrm{L}$, utilizando pHmetro LABMETER modelo $\mathrm{PH} 2$ calibrado com soluções padrão de $\mathrm{pH} 7,00$ e 4,00. Adicionou-se $100 \mathrm{mg}$ do mesocarpo em $50 \mathrm{~mL}$ das soluções com o pH previamente ajustado, e submeteu-as a agitação constante a temperatura ambiente no período de $24 \mathrm{~h}$, ao final deste tempo, as amostras foram filtradas em papel de filtro e registrou-se as medidas de $\mathrm{pH}$ final $\left(\mathrm{pH}_{\mathrm{f}}\right)$.

\subsubsection{Tempo de Equilíbrio}

Preparou-se $50 \mathrm{~mL}$ de solução do SDBS de concentração $3,5 \mathrm{mmolL}^{-1}$ no $\mathrm{pH}_{\mathrm{zpc}}$, adicionouse $0,1 \mathrm{~g}$ da farinha do mesocarpo e submeteu-se a agitação constante. $O$ tempo de equilíbrio foi estabelecido sob agitação em um período de $5 \mathrm{~h}$, sendo realizadas medições de condutividade no intervalo de 10 minutos.

\subsubsection{Efeito da Concentração}

Pesou-se $0,1 \mathrm{~g}$ do adsorvente, submeteu-se a agitação constante as soluções do surfactante com concentrações de 0,$5 ; 1,0 ; 1,5 ; 2,0 ; 2,5 ; 3,0 ; 3,5 \mathrm{mmolL}^{-1}$ em $\mathrm{pH} 6$ e tempo de equilíbrio de 5 h, em períodos de leitura de condutividade em intervalos de 10 minutos.

\section{RESULTADOS E DISCUSSÃO}

A análise condutimétrica exige um alto grau de pureza das substâncias analisadas, pois a presença de pequenas quantidades de eletrólitos alheia à solução em estudo, poderá contribuir para uma mudança significativa na condutividade, em virtude disso, realizou-se o tratamento da amostra através da lavagem da farinha do mesocarpo, com a finalidade de retirar os interferentes presentes na farinha. Na Figura 1 a seguir é possível ver o comportamento condutimétrico durante cada lavagem do mesocarpo.

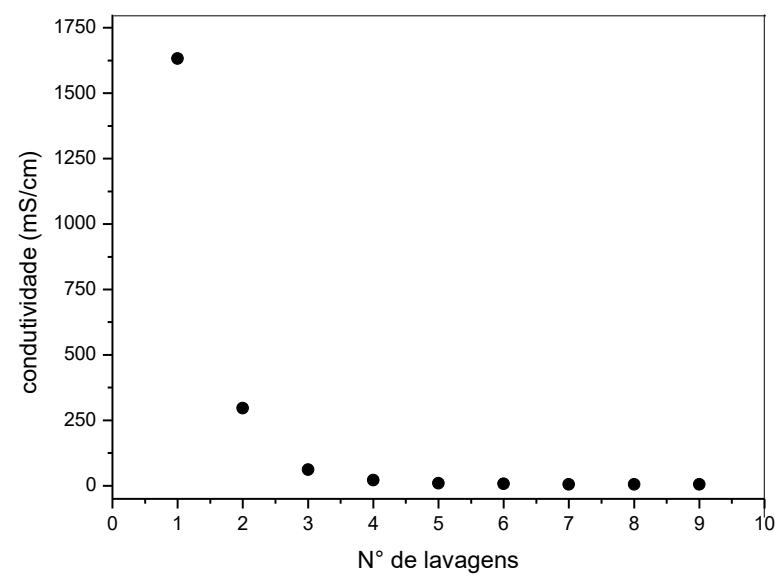

Figura 1: Comportamento da condutividade da água residual gerada pelo mesocarpo em função do número de lavagens realizadas. 
Uma grande quantidade de trabalhos que visam à adsorção de contaminantes, aplicam adsorventes sem a devida preocupação com a natureza e a influencia do mesmo com o meio na qual será aplicado. Santos (2009) demonstra sua preocupação em minimizar a influência da matéria solúvel, submetendo o mesocarpo de coco verde a consecutivas lavagens, até condutividade constante antes da aplicação na adsorção dos corantes têxteis azul remazol e turquesa remazol. O objetivo principal da lavagem é minimiza a influência de compostos solúveis em água, que contribuem para a alteração da força iônica durante as análises de adsorções, e aumenta o número de sítios ativos. Ao que se pode observar na Figura 1, é que após 4 lavagens a condutividade torna-se constante, é nesse momento que os taninos solúveis em água foram retirados do mesocarpo.

As propriedades físicas como densidade, tensão superficial, pressão osmótica, detergência e condutividade são bruscamente afetadas na concentração micelar crítica (CMC) e, portanto, podem ser utilizadas para se visualizar as formações de agregados micelares (MACDONALD, 1987). A existência dessas mudanças nas propriedades é atribuída à formação de agregados de moléculas do surfactante em determinada concentração, cuja contribuição para as propriedades físicas do sistema é diferente daquela das moléculas individuais.

A concentração micelar crítica do surfactante SDBS foi calculada a partir das medidas de condutividade das soluções preparadas em diferentes faixas de concentração. A Tabela 1 mostra os resultados de condutividade obtidos.

Tabela 1: Condutividade elétrica das concentrações do surfactante.

\begin{tabular}{cc}
\hline $\begin{array}{c}\text { Concentração } \\
\left(\mathrm{mmolL}^{-1}\right)\end{array}$ & $\begin{array}{c}\text { Condutividade } \\
(\mathrm{mS} / \mathrm{cm})\end{array}$ \\
\hline 0,5 & 27,0 \\
1,0 & 48,0 \\
1,5 & 70,2 \\
2,0 & 88,1 \\
2,5 & 113,0 \\
3,0 & 129,8 \\
3,5 & 146,5 \\
4,0 & 165,9 \\
4,5 & 174,9 \\
5,0 & 180,1 \\
5,5 & 188,6 \\
\hline
\end{tabular}

A Figura 2 mostra um gráfico típico da condutividade em função da concentração, do surfactante aniônico SDBS. 


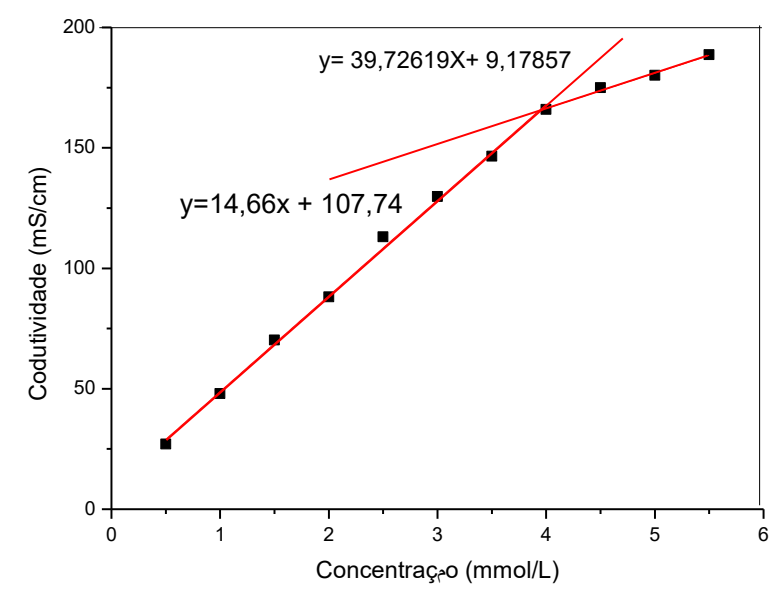

Figura 2: Concentração Micelar Crítica do surfactante.

A curva obtida em um gráfico de medida de condutividade em função da concentração do surfactante apresenta duas regiões lineares e uma inflexão, o ponto de intercepção corresponde ao valor da CMC do SDBS, calculado em $3,9 \mathrm{mmolL}^{-1}$. O processo de formação dos agregados ocorre num intervalo pequeno de concentrações, a CMC é determinada na concentração a qual ocorre uma mudança nas medidas de condutância. Abaixo da CMC, as moléculas do surfactante estão presentes na forma de monômeros, comportando-se como eletrólitos fortes o que ocasiona em um aumento linear da condutividade. Após a micelização cada monômero adicionado contribui para a formação de micelas, nem todos os contra íons estão livres em solução, o que resulta no aparecimento de uma descontinuidade das medidas de condutância.

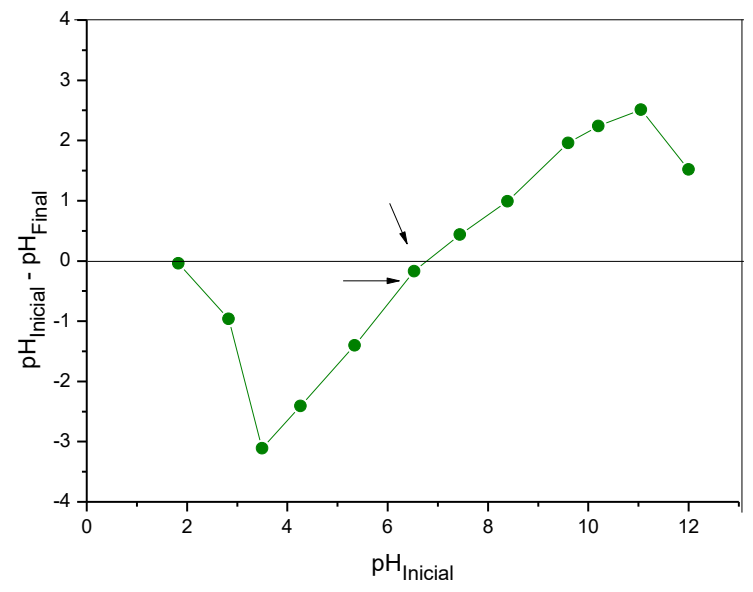

Figura 3: pH ponto de carga zero da farinha do mesocarpo.

$\mathrm{O}$ pH apresenta grande influência nos processos de adsorção. $\mathrm{O}$ pH ponto de carga zero ou $\mathrm{pH}_{\mathrm{zPC}}$ foi determinado graficamente, a partir da variação do $\mathrm{pH}$ das soluções em equilíbrio de protonação com o adsorvente $\left(\Delta \mathrm{pH}=\mathrm{pH}_{\text {Inicial }}-\mathrm{pH}_{\text {Final }}\right)$ em função do $\mathrm{pH}_{\text {Inicial, }}$, este indica o valor de $\mathrm{pH}$ no qual um determinado sólido, apresenta carga igual a zero em sua superfície. Para valores de $\mathrm{pH}$ inferiores ao $\mathrm{pH}_{\mathrm{ZPC}}$, a carga superficial é positiva e a adsorção de ânions é favorecida, e para valores de $\mathrm{pH}$ superiores ao $\mathrm{pH}_{\mathrm{ZPC}}$, a carga superficial é negativa e a adsorção de cátions é 
favorecida. A Figura 3 mostra o resultado obtido a partir da análise das alterações nos pHs das 12 soluções, após contato com $100 \mathrm{mg}$ da farinha do mesocarpo por $24 \mathrm{~h}$.

A Figura 3 mostra a avaliação da estabilidade do mesocarpo, nas diversas condições de $\mathrm{pH}$ estimado através do $\mathrm{pH}_{\mathrm{ZPC}}$, sendo que o $\mathrm{pH} \mathrm{6,5}$ foi o que apresentou menor variação, após as $24 \mathrm{~h}$ de contato da solução com a farinha do mesocarpo in natura sob agitação constante. E neste pH que a superfície do sólido mostrar-se com carga igual a zero.

As interações que ocorrem nas regiões interfaciais, influenciam decisivamente no processo de adsorção, logo a presença de cargas existentes na superfície do adsorvente em função do pH, desvirtuarão o objetivo principal da adsorção, abaixo do valor de $\mathrm{pH}_{z \mathrm{pc}}$ estimado a superfície do mesocarpo estará carregada positivamente, e acima haverá excesso de carga superficial negativa no adsorvente, com isso as análises seguintes foram realizados utilizando o $\mathrm{pH}_{\mathrm{ZPC}}$, na perspectiva de se minimizar as possíveis interferências ocasionadas pelas cargas superficiais do sólido.

A viabilidade da utilização de um material adsorvente é também determinada pela cinética de equilíbrio, o tempo para que adsorção seja atingida depende de alguns fatores como: concentração do adsorvato, quantidade do adsorvente, temperatura e velocidade de agitação. A Figura 4 mostra o comportamento da adsorção em função do tempo de contato necessário para farinha do mesocarpo in natura adsorver a capacidade máxima do surfactante nas condições empregadas.

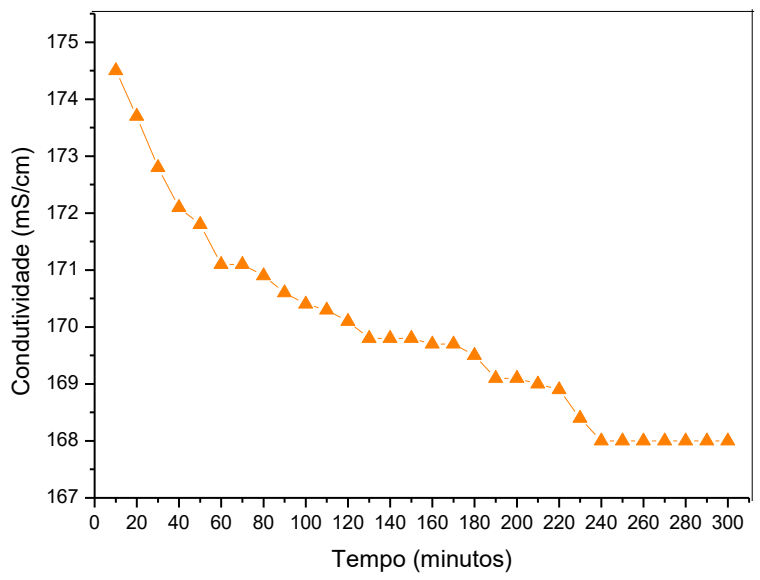

Figura 4: Cinética de equilíbrio na adsorção do surfactante SDBS frente à farinha do mesocarpo do babaçu in natura.

O estudo da cinética de equilíbrio foi realizado por meio do acompanhamento da condutividade/concentração do SDBS, demostrado no gráfico da Figura 4, onde o equilíbrio é atingido no período de contato de $240 \mathrm{~min}$, é nesse intervalo que a quantidade de surfactante adsorvida aumenta simultaneamente ao longo do período, até se tornar constante quando o equilíbrio é atingido. A diminuição da condutividade é consequência da redução do número de moléculas do tensoativo livres dispersas na solução, o que evidencia o aumento da adsorção do mesmo pela farinha do mesocarpo, no entanto para garantir as condições de equilíbrio do sistema à análise subsequente foi realizada no período de $5 \mathrm{~h}$, a partir do respectivo resultado foram calculadas a eficiência de remoção do surfactante SDBS nas diferentes concentrações. 
A eficiência da remoção foi avaliada analisando as concentrações a partir das medições de condutividade das soluções de SDBS, durante os ensaios de adsorção no período de contato estabelecido, pôde-se observar um decréscimo na condutividade, demonstrando a remoção das moléculas de tensoativos presentes na amostra. A quantidade de surfactante adsortiva por massa de adsorvente no equilíbrio foi calculada utilizando a expressão:

$$
q_{e}=\frac{\left(\mathrm{C}_{\mathrm{o}}-\mathrm{C}_{\mathrm{f}}\right) \cdot \mathrm{V}}{\mathrm{m}}
$$

Onde qe é o potencial de remoção, que é dada em mmol de adsorvato por g do adsorvente. $\mathrm{C}_{o}$ e $\mathrm{C}_{\mathrm{f}}$ são as concentrações do adsorvente $\left(\mathrm{mmol} \mathrm{L}^{-1}\right), \mathrm{m}$ a massa do adsorvente $(\mathrm{g})$ e $\mathrm{V}$ o volume da solução usada nos ensaios de adsorção (L).

Para a investigação do efeito da concentração no processo de adsorção, foram realizados experimentos variando a concentração de SDBS, o resultado obtido com este estudo está demonstrado na Figura 5.

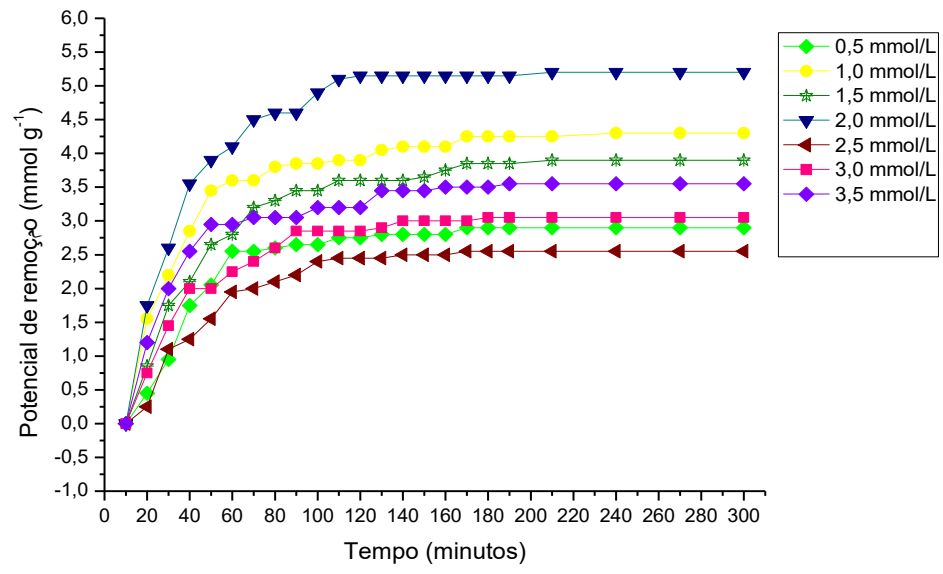

Figura 5: Potencial de remoção do surfactante em diferentes concentrações em cinética de equilíbrio de 5 h.

O potencial de remoção do surfactante, nas diferentes concentrações de SDBS pela amostra de adsorvente foi rápido no início, mas diminuiu com o tempo. Ao atingir o equilíbrio os potenciais de adsorção foram calculados para todas as amostras, as concentrações que apresentarão melhores potenciais de remoção foram às concentrações de $1,0 \mathrm{mmolL}^{-1}$ e $2,0 \mathrm{mmolL}^{-1} \mathrm{com} \mathrm{4,3} \mathrm{e}$ $5,2 \mathrm{mmol} \mathrm{g}^{-1}$ respectivamente.

O aumento da concentração resulta em um aumento na eficiência da adsorção, isso porque com o aumento da concentração, mais espécies livres estarão distribuídas na superfície do adsorvente para ser adsorvida, e em baixas concentrações existe uma grande quantidade de locais disponíveis para a adsorção, e poucas espécies livres do surfactante. Na Figura 5 observa-se, que ocorre uma dispersão nos dados das capacidades adsortivas nas diferentes concentrações, não seguindo um aumento linear de concentração/remoção. Abaixo da CMC as moléculas do tensoativo comportam-se como monômeros à medida que se aumenta a concentração, tais monômeros passam a se predispor a formar agregados micelares, o que resulta em uma diminuição da condutância da solução. 
O percentual de remoção foi calculado utilizando a seguinte expressão:

$$
A \%=\frac{C_{o}-C_{f}}{C_{o}} \times 100
$$

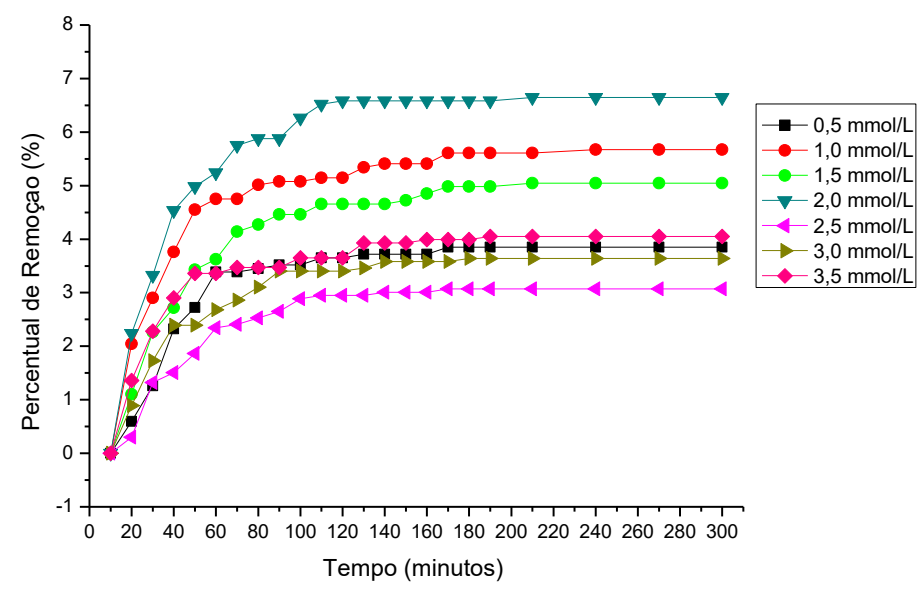

Figura 6: Percentual das capacidades adsortivas das diferentes concentrações do surfactante.

Após atingir o equilíbrio de adsorção, a percentagem foi calculada para todas as amostras, a matriz que apresentou melhor índice de remoção foi a de concentração de $2,0 \mathrm{mmolL}^{-1}$ apresentando percentual de 6,5\%.

\section{CONCLUSÃO}

A contaminação das águas naturais é uma preocupação constante e tem sido um dos grandes problemas da sociedade moderna, novas normas e legislações vêm sendo desenvolvidas, a fim de minimizar o impacto ambiental. A adsorção surge como processo eficiente para a descontaminação dos efluentes, e o mesocarpo de coco babaçu surge como uma alternativa econômica frente aos adsorventes comerciais que geralmente possuem alto custo associado à produção, além do fato deste adsorvente ser um material renovável e abundantemente disponível no nordeste. O tratamento do mesocarpo foi realizado a partir de sucessivas lavagens acompanhada pelas medidas de condutividade da água residual, após a quarta lavagem observouse a constância da condutividade, processo no qual os taninos foram removidos do adsorvente. Após as lavagens e secagem do mesocarpo foram realizados medições de condutividade para a determinação da CMC do surfactante. Com as medidas de condutividade em diferentes concentrações obteve-se duas retas e um ponto de interceptação em que se determinou a CMC com valor de 3,9 $\mathrm{mmolL}^{-1}$, a partir do valor da CMC foi possível realizar as analises em concentrações abaixo desta. $\mathrm{O}$ pH ZPC foi obtido graficamente após o período de contato de $24 \mathrm{~h}$ do mesocarpo com surfactante com pHs previamente ajustados com valor de 6,5. O tempo de equilíbrio foi de $240 \mathrm{~min}$. Com os valores de $\mathrm{pH}_{z p c}$ e tempo de equilíbrio, determinou-se a capacidade adsortiva do mesocarpo in natura frente ao surfactante SDBS nas diferentes 


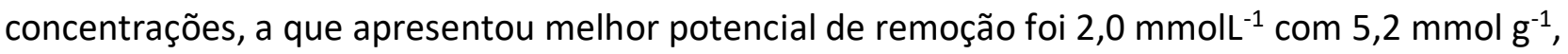
e 6,5\% como percentual desta remoção.

\section{REFERÊNCIAS BIBLIOGRÁFICAS}

1. AIROLD, C.; VIEIRA, A. P.; SANTANA, S. A. A.; BEZERRA, C. W. B.; SILVA, H. A. S.; CHAVES, J. A. P.; FILHO, E. C. S. Kinetics and thermodynamics of textile dye adsorption from aqueous solutions using babassu coconut mesocarp. Journal of Hazardous Materials, v.166, p.12721278, 2009.

2. BEZERRA, J. M. M. Síntese de Tensoativo para a Extração de Metal Pesado. [Monografia]. Rio Grande do Norte: Universidade Federal Rural Do Semiárido; 2012.

3. BONAM, A. A.; KOROISHI, E. T. e SILCA, C. F.; Remoção de corantes reativos de efluentes de indústrias têxteis utilizando diferentes adsorventes. Anais do III encontro brasileiro sobre adsorção (Recife - PE), 217-221, 2002.

4. BRAGA, B.; HESPANHOL, I.; CONEJO, J. G. L.; BARROS, M. T.; SPENCER, M.; PORTO, M.; NUCCI, N.; JULIANO, N.; EIGER, S. Introdução à Engenharia Ambiental. Prentice Hall, São Paulo, p 305. 2002.

5. BRUNDTLAND, G.H. Nosso futuro comum. Relatório da Comissão Mundial sobre MeioAmbiente e Desenvolvimento. ONU. Ed. Fundação Getúlio Vargas. Rio de Janeiro. 1991, p 430.

6. CARRAZZA, L. R.; ÁVILA, J. C. C.; SILVA, M. L. Manual Tecnológico de Aproveitamento Integral do Fruto e da Folha do Babaçu (Attalea ssp.). Instituto Sociedade, População e Natureza. 2012

7. EICHHORN, P.; RODRIGUES, S. V.; BAUMANN, W.; KNEPPER, T. P. Incomplete degradation of linear alkylbenzene sulfonate surfactants in Brazilian surface waters and pursuit of their polar metabolites in drinking waters. The Science of The Total Environment, v. 284, p. 123134. 2002.

8. HOLMBERG, B.; JONSSON, B.; KRONBERG, B.; LINDMAN, E. Surfactants and polymers in aqueous solutions. John Wiley and Son, 2 ed. Ltd, 2003.

9. KUMAR, K. V.; VADIVELAN, V. Equilibrium kinetics, mechanism, and process design for the sorption of methylene blue onto rice husk. Journal of Colloid and Interface Science, v. 286, p. 90-100, 2005.

10. KUNZ, A. Novas Tendências no Tratamento de Efluentes Têxteis. Química Nova, v. 25, n. 1, p. 78-82. 2002.

11. MACDONALD, J.R. Impedance Spectroscopy. John Wiley \& Sons, Nova York, 1987.

12. MARCOS, A. N. F. O total aproveitamento do coco babaçu (Orbignya oleifera). [Monografia]. Brasília: Universidade de Brasília; 2011.

13. NANDI, B. K.; GOSWAMI, A.; PURKAIT, M. K. Removal of cationic dyes from aqueous solutions by kaolin: Kinetic and equilibrium studies. Applied Clay Science, v. 42, p.583-591. 2008.

14. OLIVEIRA, C. C. Neves de. Estudos de equilíbrio e modelagem cinética de adsorção de corante têxtil remazol black $B$ sobre bagaço da cana de açúcar e carvão ativado. Dissertação (Mestrado em Química). Pernambuco. 2003.

15. PIRES, P. A. R. Sínteses e Propriedades de soluções de Tensoativos Catiônicos Derivados de 
(3-Dimetilaminopropil)amidas de ácidos carboxílicos. [Tese de Doutorado]. São Paulo: Universidade de São Paulo; 2002.

16. SANTOS, D. O. Mesocarpo do coco verde: caracterização e potencialidade de adsorção frente a corantes da indústria têxtil. Trabalho de Conclusão de Curso apresentado como requisito parcial à obtenção do título de química industrial. Universidade Federal do Maranhão. São Luis, 2009.

17. SHIPOVSKOV, S.; TROFIMOVA, D.; SAPRYKIN, E.; CHRISTENSON, A.; RUZAS, T.; LEVASHOV, A.V.; FERAPONTOVA, E. E. Spraying enzimes in microemulsions of AOT in nonpolar organic solvents for fabrication of enzyme electrodes. Analytical Chemistry, v. 77, p. 7074-7079. 2005.

18. SOUSA, F. W.; MOREIRA, S. A.; OLIVEIRA, A. G.; TADROS, T. F. Applied surfactants: principles and applications. Wiley-VCH, Weinheim, 2005.

19. TADROS, T.F. Applied surfactants: principles and applications. Wiley-VCH, Weinheim, 2005.

20. TAFFAREL, S. R.; GOMES. C. S.; RUBIO, J. Remoção de surfactante aniônico de soluções aquosas por organo-zeólita. Universidade Federal do Rio Grande do Sul. In: XVIII Congresso Brasileiro de Engenharia Química. 2010, p 1903-1912.

21. VIEIRA, A. P.; SANTANA, S. A. A.; BEZERRA, C. W. B.; SILVA, H. A. S.; CHAVES, J. A. P.; MELO, J. C. P.; SILVA, E. C. F.; AIROLDI, C. Kinetics and thermodynamics of textile dye adsorption from aqueous solutions using babassu coconut mesocarp. Journal of Hazardous Materials, v. 166, p. 1272-1278, 2009b.

22. YOSHIMURA, T.; MATSUO, K.; FUJIOKA, R. Novel biodegradable superabsorbent hydrogels derived from cotton cellulose and succinic anhydride: synthesis and characterization. Journal pf Applied Polymer Science, v. 99, p. 3251-3256, 2006.

23. ZHENG, Z.; OBBARD, E J.P. PAHs removal from soil by surfactant solubilization and P. chrysosporium oxidation. Environmental Quality, v. 31, p. 1842-1847. 2002. 